\title{
In-Hospital Outcomes of Female Patients With Inferior Wall Myocardial Infarction
}

Ghulam Kubra ${ }^{1}$, Tahir Saghir ${ }^{2}$, Shazia Rasheed ${ }^{3}$, Fariha Hasan Rehan ${ }^{2}$, Asad Ali ${ }^{2}$, Syed Abbas ${ }^{2}$

1. Electrophysiology, National Institute of Cardiovascular Diseases, Karachi, PAK 2. Cardiology, National Institute of Cardiovascular Diseases, Karachi, PAK 3. Echocardiography, National Institute of Cardiovascular Diseases, Karachi, PAK

Corresponding author: Ghulam Kubra, dockubrakhaliq@yahoo.com

\section{Abstract}

\section{Background}

The aim of this study was to determine the in-hospital outcome of female patients with inferior wall myocardial infarction (MI).

\section{Methodology}

This study was conducted from January to December 2017 at the Department of Cardiology, National Institute of Cardiovascular Disease, Karachi. A total of 59 women admitted with inferior wall MI were enrolled in the study. In all patients, in-hospital outcomes were observed. Descriptive statistics were applied. Stratification was done using chi-square test, and $p$-value of $\leqslant 0.05$ was considered significant.

\section{Results}

The mean age of study participants was $58.80 \pm 9.17$ years, while 247 (79.7\%) participants were above 50 years of age. The mean onset of duration of sign and symptoms of inferior wall MI was $3.48 \pm 1.53$ hours. There were 36 (61.0\%) patients who had diabetes mellitus, 46 (78.0\%) had hypertension, 17 (28.8\%) were obese, nine (15.3\%) had a family history of MI, and three (5.1\%) were smokers. There were 43 ( $72.9 \%)$ patients who were illiterate. In our study, eight (13.6\%) females were found to have sinus bradycardia, seven (11.9\%) had sinus tachycardia, three (5.1\%) had atrial fibrillation, and 24 (40.7\%) had complete heart block. Mortality was noted in five ( $8.5 \%)$ patients.

\section{Conclusions}

Women with an acute inferior wall MI had a higher rate of complete heart block and adverse in-hospital outcomes. Female gender itself with inferior wall MI may be at risk for in-hospital adverse outcomes.

Review began 01/27/2021 Review ended 02/07/2021 Published 02/11/2021

\section{() Copyright 2021}

Kubra et al. This is an open access article distributed under the terms of the Creative Commons Attribution License CC-BY 4.0., which permits unrestricted use, distribution, and reproduction in any medium, provided the original author and source are credited.

\section{Categories: Cardiology}

Keywords: inferior wall mi, female, outcome, complete heart block

\section{Introduction}

Ischemic heart disease (IHD) is known to have a wide clinical spectrum that ranges from stable angina through unstable angina to myocardial infarction (MI) [1]. IHD has been found to be more prevalent among male patients [2]. Common risk factors for IHD are diabetes, hypertension, smoking, hyperlipidemia, and family history of IHD. MI is the necrosis of myocytes because of disruption in the blood supply [2,3]. MI can be anterior, inferior, lateral, or posterior walls of left ventricle depending upon the vessel supplying the area $[4]$.

Inferior wall MI has been found to account for 40-50\% of acute MI cases; however, they have better favorable outcomes compared to other types of MI, for example, mortality ranges between $2 \%$ and $9 \%$ in these cases [5]. Around $50 \%$ of patients having inferior wall MIs are thought to have complications that significantly amend favorable prognosis [6]. Patient with inferior wall MIs having precordial ST segment depression, complete atrioventricular block (AVB), or right ventricular infarction (RVI) are high-risk group patients as they have a larger area at risk $[7,8]$. Inferior wall MI and heart block are thought to result in increased incidence of early mortality. Multi-vessel disease and high-grade blockage of the left anterior descending coronary artery have been found in about $90 \%$ of the cases developing complete AV blockage after inferior wall MI [9]. In comparison to anterior wall MIs, bradyarrhythmias occur more frequently among patients of inferior wall MIs. Sinus bradycardias are the most prevalent type of bradyarrhythmias seen in four to six hours among patients of acute MIs [10]. AVB occurs in 9-33\% of inferior wall MI cases, while blockage or early onset generally lasts for a short duration [11].

A study from Iran concluded that rates of heart failure and in-hospital deaths increased among female 
gender [12]. According to the American Heart Association, mortality burden has been found to be more among females since 1984 [13]. Gender differences occur in terms of pathophysiology as well as clinical presentation of MIs and have been found to result in treatment delays [13]. The current study aimed to determine the in-hospital outcomes of female patients with inferior wall MI.

\section{Materials And Methods}

This study was conducted from January to December 2017 at the Department of Cardiology, National Institute of Cardiovascular Disease, Karachi. Approval from institutional ethical review board was acquired. Written consent was taken from all enrolled patients or from their guardians.

A total of 59 female patients aged 35-80 years with inferior wall MI and presenting within three days of having symptoms of inferior wall MI were enrolled. The diagnosis of inferior wall MI was labeled as the presence of ST segment elevation in leads I, II, and aVF; Q waves more than $>0.04$ seconds in duration in lead I, II, and aVF; or reciprocal ST segment depression in the lateral and/or high lateral leads (I, aVL, V5, and V6) and at least one of the following: (1) chest pain considered characteristic of myocardial ischemia, and (2) elevation of troponin I and/or CKMB for $\leqslant 12$ hours, with or without heart block. Patients having cardiac arrest assessed by history and electrocardiogram changes were excluded. According to history and clinical assessment, patients having other causes of shock such as hypovolemia, hemorrhage, sepsis, pulmonary embolism, or anaphylaxis were not enrolled. All female patients having shock because of mechanical complications to MI or having severe aorta valve regurgitation/stenosis were also excluded.

Data regarding gender, age, past history of MI, congestive heart failure, angina, hypertension, diabetes, or smoking were noted. In all patients, outcomes (i.e., sinus bradycardia, sinus tachycardia, atrial fibrillation, complete heart block, and death) were recorded during the hospital stay. Sinus bradycardia was defined as regular but unusually slow heart beat (50 beats/minute or less at rest). Sinus tachycardia was defined as elevated rate of impulses, defined as a rate greater than 100 beats/minute in an average adult. Atrial fibrillation was described as absence of P-waves and presence of QRS complexes in an irregular rhythm with or without the presence of coarse or fine fibrillatory waves. Complete heart block was labeled as complete absence of AV conduction, where none of the supraventricular impulses are conducted to the ventricles. Mortality was noted within three days of hospital stay and described as more than five minutes of no signs of life, including no blood pressure, no pulse, no cardiac and respiratory sounds, and pupils bilateral dilated and fixed. All cases were considered for thrombolytic agents if there was no known contraindication. If any complications occurred, they were managed as per the institutional protocols.

All study data were recorded on a predesigned proforma. SPSS version 19.0 (IBM, Armonk, NY, USA) was used for data analysis. Frequencies and percentages were calculated for qualitative variables including diabetes mellitus, hypertension, smoking, obesity, educational status, and outcome. Mean and standard deviation (SD) were calculated for quantitative variables including age and duration of symptoms. Effect modifier including age, diabetes mellitus, hypertension, smoking, obesity, educational status, and duration of symptoms of inferior wall MI were controlled through stratification. Post-stratification chi-square test was applied considering a p-value of $\leqslant 0.05$ as significant.

\section{Results}

The mean age of study participants was $58.80 \pm 9.17$ years, while $47(79.7 \%)$ patients were above 50 years of age. The mean onset of duration of signs and symptoms of inferior wall MI was $3.48 \pm 1.53$ hours. There were $36(61.0 \%)$ patients who had diabetes mellitus, 46 (78.0\%) had hypertension, 17 (28.8\%) were obese, nine (15.3\%) had a family history of MI, and three (5.1\%) were smokers. There were 43 (72.9\%) patients who were illiterate.

In our study, eight (13.6\%) females were found to have sinus bradycardia, seven (11.9\%) had sinus tachycardia, three (5.1\%) had atrial fibrillation, and 24 (40.7\%) had complete heart block. Mortality was noted in five $(8.5 \%)$ patients.

Stratification with respect to age, duration of onset, diabetes mellitus, hypertension, obesity, family history of MI, smoking status, and educational status was done to observe the effect of these modifiers on inhospital outcomes (Tables 1, 2, 3). Significant association of tachycardia was noted with obesity $(p=0.009)$. Atrial fibrillation had significant association with increasing age $(\mathrm{p}=0.041)$. Complete heart block was found to have significant association with increasing age $(\mathrm{p}=0.040)$. Mortality was noted to have significant association with family history of MI $(\mathrm{p}=0.004)$. 


\section{Cureus}

\begin{tabular}{|c|c|c|c|c|c|c|}
\hline \multirow{2}{*}{ Study variables } & \multicolumn{3}{|c|}{ Sinus bradycardia } & \multicolumn{3}{|c|}{ Sinus tachycardia } \\
\hline & Yes $(n=8)$ & No $(n=51)$ & P-Value & Yes $(n=7)$ & No $(n=52)$ & P-Value \\
\hline \multicolumn{7}{|l|}{ Age } \\
\hline$\leq 50$ years & 1 (12.5\%) & $11(21.6 \%)$ & \multirow{2}{*}{0.554} & 2 (28.6\%) & 10 (19.2\%) & \multirow{2}{*}{0.564} \\
\hline$>50$ years & 7 (87.5\%) & 40 (78.4\%) & & 5 (71.4\%) & 42 (80.8\%) & \\
\hline \multicolumn{7}{|l|}{ Onset duration } \\
\hline$\leq 3$ hours & 3 (37.5\%) & $26(51.0 \%)$ & \multirow{2}{*}{0.478} & 3 (42.9\%) & 26 (50.0\%) & \multirow{2}{*}{0.722} \\
\hline$>3$ hours & $5(42.5 \%)$ & 25 (49.0\%) & & $4(57.1 \%)$ & 26 (50.0\%) & \\
\hline Diabetes mellitus & $5(62.5 \%)$ & 31 (60.8\%) & 0.926 & 5 (71.4\%) & 31 (59.6\%) & 0.547 \\
\hline Hypertension & 7 (87.5\%) & 39 (76.5\%) & 0.484 & 6 (85.7\%) & 40 (76.9\%) & 0.598 \\
\hline Obesity & 2 (25.0\%) & 15 (29.4\%) & 0.798 & 4 (57.1\%) & 13 (25.0\%) & 0.009 \\
\hline Family history of MI & $1(12.5 \%)$ & 8 (15.7\%) & 0.934 & 1 (14.3\%) & 8 (15.4\%) & 0.939 \\
\hline Smoker & $1(12.5 \%)$ & $2(3.9 \%)$ & 0.304 & $0(0 \%)$ & $3(5.8 \%)$ & 0.514 \\
\hline Illiterate & $6(75.0 \%)$ & 37 (72.5\%) & 0.885 & $5(71.4 \%)$ & 38 (73.1\%) & 0.927 \\
\hline
\end{tabular}

TABLE 1: Distribution of sinus bradycardia and sinus tachycardia with respect to study variables.

MI, myocardial infarction

\begin{tabular}{|c|c|c|c|c|c|c|}
\hline \multirow{2}{*}{ Study variables } & \multicolumn{3}{|c|}{ Atrial fibrillation } & \multicolumn{3}{|c|}{ Complete heart block } \\
\hline & Yes $(n=3)$ & No $(n=56)$ & P-Value & Yes $(n=24)$ & No $(n=35)$ & P-Value \\
\hline \multicolumn{7}{|l|}{ Age } \\
\hline$\leq 50$ years & 2 (33.3\%) & $10(17.9 \%)$ & \multirow{2}{*}{0.041} & 8 (33.3\%) & $4(11.4 \%)$ & \multirow{2}{*}{0.04} \\
\hline$>50$ years & $1(66.7 \%)$ & 46 (82.1\%) & & $16(66.7 \%)$ & 31 (88.6\%) & \\
\hline \multicolumn{7}{|l|}{ Onset duration } \\
\hline$\leq 3$ hours & $1(33.3 \%)$ & $28(50.0 \%)$ & \multirow{2}{*}{0.574} & $13(54.2 \%)$ & 16 (45.7\%) & \multirow{2}{*}{0.524} \\
\hline$>3$ hours & $2(66.7 \%)$ & 28 (50.0\%) & & $11(45.8 \%)$ & 19 (54.3\%) & \\
\hline Diabetes mellitus & 2 (33.3\%) & $34(60.7 \%)$ & 0.837 & 14 (58.3\%) & $22(62.9 \%)$ & 0.726 \\
\hline Hypertension & $2(66.7 \%)$ & 44 (78.6\%) & 0.628 & $20(83.3 \%)$ & $26(74.3 \%)$ & 0.41 \\
\hline Obesity & $2(66.7 \%)$ & $15(26.8 \%)$ & 0.137 & $11(45.8 \%)$ & 6 (17.1\%) & 0.017 \\
\hline Family history of MI & $1(33.3 \%)$ & $8(14.3 \%)$ & 0.371 & $3(12.5 \%)$ & 6 (17.1\%) & 0.237 \\
\hline Smoker & $0(0 \%)$ & $3(5.4 \%)$ & 0.386 & 2 (83.3\%) & $1(2.9 \%)$ & 0.347 \\
\hline Illiterate & $2(66.7 \%)$ & 41 (73.2\%) & 0.804 & 17 (70.8\%) & 26 (74.3\%) & 0.77 \\
\hline
\end{tabular}

TABLE 2: Distribution of atrial fibrillation and complete heart block with respect to study variables.

MI, myocardial infarction 


\section{Cureus}

\begin{tabular}{|c|c|c|c|}
\hline \multirow{2}{*}{ Study variables } & \multicolumn{3}{|l|}{ Mortality } \\
\hline & Yes $(\mathrm{n}=5)$ & No $(n=54)$ & P-Value \\
\hline \multicolumn{4}{|l|}{ Age } \\
\hline$\leq 50$ years & $2(40.0 \%)$ & $10(18.5 \%)$ & \multirow{2}{*}{0.254} \\
\hline$>50$ years & $3(60.0 \%)$ & $44(81.5 \%)$ & \\
\hline \multicolumn{4}{|l|}{ Onset duration } \\
\hline$\leq 3$ hours & $2(40.0 \%)$ & $27(50.0 \%)$ & \multirow{2}{*}{0.669} \\
\hline$>3$ hours & $3(60.0 \%)$ & $27(50.0 \%)$ & \\
\hline Diabetes mellitus & $3(60.0 \%)$ & $33(61.1 \%)$ & 0.961 \\
\hline Hypertension & $4(80.0 \%)$ & $42(77.8 \%)$ & 0.909 \\
\hline Obesity & $3(60.0 \%)$ & $14(25.9 \%)$ & 0.108 \\
\hline Family history of MI & $3(60.0 \%)$ & $6(11.1 \%)$ & 0.004 \\
\hline Smoker & $1(20.0 \%)$ & $2(3.7 \%)$ & 0.113 \\
\hline Illiterate & $4(80.0 \%)$ & $39(72.2 \%)$ & 0.108 \\
\hline
\end{tabular}

TABLE 3: Distribution of artial fibrillation and complete heart block with respect to study variables.

MI, myocardial infarction

\section{Discussion}

Although age-adjusted death rates have been found to be decreasing among developed countries, death rates are rising in Pakistan [14]. Timely detection, hemodynamic support, rapid reperfusion treatment, and ideas about the most probable complications of acute MI can assist in improving the outcome among these patients [15]. Advanced age has been linked with poor short-term prognosis in patients having acute MI [16]. These patients could be less likely to get reperfusion therapy or adjunctive treatment. Gurwtiz and colleagues noted progressive decline in the administration of thrombolytic therapy with advancing age [17]. Clinicians are hesitant to utilize thrombolytic agents in older patients as these patients are found to have delayed presentation, unfamiliar time of symptom onset, increased chances of bleeding, and relative contraindication to thrombolytic agents [18].

After adjusting confounding variables, old age has been marked to be an independent predictor of inhospital death among patient having acute MI [19]. In the present study, 79.7\% female patients were found to be aged above 50 years. Jim et al. noted increasing age to be significantly associated with in-hospital mortality among female patients [20]. Presentation after 24 hours and use of $\beta$-blockers have also been linked with mortality [20]. Although this study did not make any comparison in terms of gender, it has been found by previous researchers that female patients below 75 years of age have two-fold increased chances of in-hospital mortality; however, the difference in mortality pattern was not significant after 75 years of age [21]. Recent local data have found that patients having inferior wall acute MI are more prone to have AV nodal conduction issues [22]. Ravikumar et al. noted $60 \%$ of the cases where arrhythmias occurred within the first 12 hours of admission [23]. Some researchers have revealed that around $90 \%$ of the patients showed cardiac conduction abnormalities within 24 hours following acute MI [24]. In our study, 13.6\% females were found to have sinus bradycardia, $11.9 \%$ sinus tachycardia, $5.1 \%$ atrial fibrillation, and $40.7 \%$ had complete heart block. Compared to previous findings, regional data indicate that incidence of conduction blocks has been found to be increasing among patients with inferior wall MI, while AVB and RVI were found to be significantly linked with poor outcomes [25]. Berger and Ryan revealed three high-risk subgroups, namely, complete AV block, precordial ST-segment depression and RVI, among patients having inferior wall MI [7]. Jim et al. found complete AVB to predict in-hospital mortality with an odds ratio of 3.9, whereas its linkage with unfavorable outcomes have been well documented in previous studies [20]. This could be due to the relation of complete AVB with large infarct areas.

In the present study, mortality was noted in $8.5 \%$ of the patients which is lower than that found previously (13.4\%) in a local study [15]. Short-term mortality rates between $12 \%$ and $23 \%$ have been noted among patients with acute inferior wall MI [26]. 
As this was a single center study conducted at an urban healthcare facility with a relatively shorter sample size, the findings cannot be generalized. We also did not have any randomization or control design in the present study. We were also unable to detail management protocols and their linkage with the outcome as this was beyond the scope of our study.

\section{Conclusions}

Women with an acute inferior wall MI had higher rates of complete heart block and adverse in-hospital outcomes. Female gender itself with inferior wall MI could be at risk for short-term in-hospital poor outcomes. Further studies are needed to further confirm the gender differences and appropriate management protocols among patients presenting with inferior wall acute MI.

\section{Additional Information \\ Disclosures}

Human subjects: Consent was obtained or waived by all participants in this study. National Institute of Cardiovascular Diseases (NICVD), Karachi, Pakistan issued approval NA. Animal subjects: All authors have confirmed that this study did not involve animal subjects or tissue. Conflicts of interest: In compliance with the ICMJE uniform disclosure form, all authors declare the following: Payment/services info: All authors have declared that no financial support was received from any organization for the submitted work. Financial relationships: All authors have declared that they have no financial relationships at present or within the previous three years with any organizations that might have an interest in the submitted work. Other relationships: All authors have declared that there are no other relationships or activities that could appear to have influenced the submitted work.

\section{References}

1. Brewer LC, Svatikova A, Mulvagh SL: The challenges of prevention, diagnosis and treatment of ischemic heart disease in women. Cardiovasc Drugs Ther. 2015, 29:355-68. 10.1007/s10557-015-6607-4

2. Sakboonyarat B, Rangsin R: Prevalence and associated factors of ischemic heart disease (IHD) among patients with diabetes mellitus: a nation-wide, cross-sectional survey. BMC Cardiovasc Disord. 2018, 18:151. 10.1186/s12872-018-0887-0

3. Rashid NA, Nawi AM, Khadijah S: Exploratory analysis of traditional risk factors of ischemic heart disease (IHD) among predominantly Malay Malaysian women. BMC Public Health. 2019, 19:545. 10.1186/s12889019-6855-5

4. Roger VL: Epidemiology of myocardial infarction. Med Clin North Am. 2007, 91:537-52. 10.1016/j.mcna.2007.03.007

5. Aguiar RS, Timóteo AT, Ferreira L, et al.: Complete atrioventricular block in acute coronary syndrome: prevalence, characterisation and implication on outcome. Eur Heart J Acute Cardiovasc Care. 2018, 7:218-23. $10.1177 / 2048872617716387$

6. Hubbard J: Complications associated with myocardial infarction. Nurs Times. 2003, 99:28-9.

7. Berger PB and Ryan TJ: Inferior myocardial infarction: high-risk subgroups. Circulation. 1990, 81:401-11. 10.1161/01.cir.81.2.401

8. Andersen HR, Nielsen D, Lund O, Falk E: Prognostic significance of right ventricular infarction diagnosed by ST elevation in right chest leads V3R to V7R. Int J Cardiol. 1989, 23:349-56. 10.1016/0167-5273(89)90195-2

9. Bassan R, Maia IG, Bozza A, Amino JGC, Santos M: Atrioventricular block in acute inferior wall myocardial infarction: harbinger of associated obstruction of the left anterior descending coronary artery. J Am Coll Cardiol. 1986, 8:773-8. 10.1016/s0735-1097(86)80416-8

10. O'Doherty M, Taylor DI, Quinn E, Vincent R, Chamberlain DA: Five hundred patients with myocardial infarction monitored within one hour of symptoms. Br Med J (Clin Res Ed). 1983, 286:1405-8. 10.1136/bmj.286.6375.1405

11. Courter SR, Moffat J, Fowler NO: Advanced atrioventricular block in acute myocardial infarction. Circulation. 1963, 27:1034-42. 10.1161/01.cir.27.6.1034

12. Ghaffari S, Pourafkari L, Tajlil A, Bahmani-Oskoui R, Nader ND: Is female gender associated with worse outcome after ST elevation myocardial infarction?. Indian Heart J. 2017, 169:28-33. 10.1016/j.ihj.2016.12.003

13. Mehta LS, Beckie TM, DeVon HA, et al.: Acute myocardial infarction in women: A scientific statement from the American Heart Association. Circulation. 2016, 133:916-47. 10.1161/CIR.0000000000000351

14. Afreen A, Khan MN, Khan MB, Ahmad A, Akbar MS, Danyal SM: S82 risk factor assessment in patients undergoing coronary angiography at army cardiac centre Lahore. Pak Armed Forces Med J. 2019, 69:82-6.

15. Khan IS, Malik MN, Afzal M: The effect of right ventricular infarction on clinical outcome of inferior wall myocardial infarction. Ann Pak Inst Med Sci. 2013, 9:91-4.

16. Maggioni AP, Maseri A, Fresco C, Franzosi MG, Mauri F, Santoro E, Tognoni G: Age-related increase in mortality among patients with first myocardial infarctions treated with thrombolysis. The Investigators of the Gruppo Italiano per lo Studio della Sopravvivenza nell'Infarto Miocardico (GISSI-2). N Engl J Med. 1993, 329:1442-8. 10.1056/NEJM199311113292002

17. Gurwitz JH, Gore JM, Goldberg RJ, Rubison M, Chandra N, Rogers WJ: Recent age-related trends in the use of thrombolytic therapy in patients who have had acute myocardial infarction. National Registry of Myocardial Infarction. Ann Intern Med. 1996, 124:283-91. 10.7326/0003-4819-124-3-199602010-00001

18. Gurwitz JH, Goldberg RJ, Chen Z, Gore JM, Alpert JS: Betablocker therapy in acute myocardial infarction: evidence for underutilization in the elderly. Am J Med. 1992, 93:605-10. 10.1016/0002-9343(92)90192-e

19. Goldberg RJ, McCormick D, Gurwitz JH, Yarzebski J, Lessard D, Gore JM: Age-related trends in short- and 


\section{Cureus}

long-term survival after acute myocardial infarction: a 20 -year population-based perspective (1975-1995). Am J Cardiol. 1998, 82:1311-7. 10.1016/s0002-9149(98)00633-x

20. Jim MH, Chan AO, Tse HF, Lau CP: Predictors of inhospital outcome after acute inferior wall myocardial infarction. Singapore Med J. 2009, 50:956-61.

21. Vakili BA, Kaplan RC, Brown DL: Sex-based differences in early mortality of patients undergoing primary angioplasty for first acute myocardial infarction. Circulation. 2001, 104:3034-8. 10.1161/hc5001.101060

22. Khan M, Khan IA, Samore NA, et al.: Clinical outcome of patients admitted with acute anterior versus acute inferior wall myocardial infarction. Pak Armed Forces Med J. 2020, 70:892-6.

https://mail.pafmj.org/index.php/PAFMJ/article/view/6050

23. Ravikumar TN, Anikethana GV: Study of arrhythmias in acute inferior wall myocardial infarction . J Evid Based Med Healthcare. 2014, 1:533-8.

24. Aufderheide TP: Arrhythmias associated with acute myocardial infarction and thrombolysis . Emerg Med Clin North Am. 1998, 16:583-600. 10.1016/s0733-8627(05)70019-5

25. Kumar V, Sinha S, Kumar P, et al.: Short-term outcome of acute inferior wall myocardial infarction with emphasis on conduction blocks: a prospective observational study in Indian population. Anatol J Cardiol. 2017, 17:229-34. 10.14744/AnatolJCardiol.2016.6782

26. Pirzada AM, ZamanKS, Mahmood K, Sagheer T, Mahar SA, Jafri MH: High degree atrioventricular block in patients with acute inferior myocardial infarction with and without right ventricular involvement. J Coll Physicians Surg Pak. 2009, 19:269-74. 